Waste and Resource Management Volume 165 Issue WR3

Landfill capping stability: tapered solution with seepage

Zhang, Fowmes and Jones
Proceedings of the Institution of Civil Engineers

Waste and Resource Management 165

August 2012 Issue WR3

Pages 141-149 http://dx.doi.org/10.1680/warm.11.00007

Paper 1100007

Received 21/06/2011

Accepted 21/03/2012

Keywords: geotextiles, membranes \& geogrids/landfill

\title{
Landfill capping stability: tapered solution with seepage
}

1 Bo Zhang MSc, PhD

Geotechnical Engineer, Golder Associates (UK) Ltd, Stanton-on-the-Wolds, Nottinghamshire, UK

2 Gary Fowmes MSc, EngD

Senior Geotechnical Engineer, FCC Environment, Nuneaton, UK
3 D. Russell V. Jones MSc, MA, PhD

Senior Geotechnical Engineer, Golder Associates (UK) Ltd, Stanton-on-the-Wolds, Nottinghamshire, UK
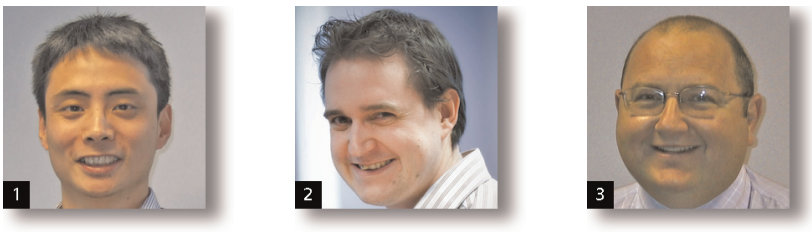

The capping system is one of the major structural elements in modern landfills. When using artificial sealing materials (e.g. a geomembrane) as the capping liner, the stability of the cover soils and integrity of the geosynthethics need to be assessed. Traditional design methods only consider uniform cover soil thickness with different degrees of saturation and seepage build-up (i.e. parallel submergency ratio). This paper proposes an analytical method which includes the seepage build-up in the stability analysis for the capping slope with a tapered cover soil profile, that is when cover soils become thicker from top to bottom. Both the parallel (modified) and horizontal seepage force build-up patterns have been considered and analysed. The proposed analytical methods are applied to a design case in which uniform thickness cover soils are considered. The results are comparable to those of the traditional methods and therefore they are verified. Parametric analyses have confirmed the tapered profile can effectively improve the capping slope stability and indicated that the interface shear strength (between the cover soil and the underlying geosynthetic) and cover soil shear strength have the most significant effects on the capping slope stability.

\section{Notation}

C cohesion force between cover soil of the passive wedge and the base soil

$C_{\alpha} \quad$ adhesion force between cover soil of the active wedge and the geomembrane

$c^{\prime} \quad$ effective cohesion of the cover soil

$D \quad$ thickness of cover soil at bottom of the slope, measured vertically

$E_{\mathrm{A}} \quad$ interwedge force acting on the active wedge

$E_{\mathrm{P}} \quad$ interwedge force acting on the passive wedge

FS factor of safety

$H \quad$ total height of slope

$H_{\mathrm{w}}$ height of horizontal water table

$H_{\mathrm{c}} \quad$ height of tapered soil between active and passive wedges

$h_{\mathrm{c}} \quad$ thickness of cover soil at crest of the slope, measured perpendicular to the slope

$h_{\mathrm{w}}$ thickness of saturated cover soil at crest of the slope, measured perpendicular to the slope

$L \quad$ length of slope measured along the geomembrane

$N_{\mathrm{A}}$ effective force normal to the failure plane of the active wedge
$N_{\mathrm{P}} \quad$ effective force normal to the failure plane of the passive wedge

$U_{\mathrm{h}}$ resultant of the pore pressures acting on the interwedge surfaces

$U_{\mathrm{n}} \quad$ resultant of the pore pressures acting perpendicular to the slope

$U_{\mathrm{v}} \quad$ resultant of the vertical pore pressures acting on the passive wedge

$W_{\mathrm{A}}$ total weight of the active wedge

$W_{\mathrm{P}}$ total weight of the passive wedge

adhesion between cover soil of the active wedge and the geomembrane

$\beta \quad$ soil slope angle beneath the geomembrane

$\delta \quad$ interface friction angle between cover soil and geomembrane

$\gamma_{\mathrm{d}} \quad$ dry unit weight of the cover soil

$\gamma_{\text {sat }} \quad$ saturated unit weight of the cover soil

$\varphi \quad$ friction angle of the cover soil

$\omega \quad$ final cover soil slope angle (note that $\omega \leq \beta$ ) 


\section{Introduction}

When a proposed landfill capping soil slope above the artificial sealing layer (e.g. geomembrane) is considered to be unstable, it is not unusual to make the slope shallower by placing more cover soil, so that it is thicker at the bottom and gradually thinner going towards the top. In this case, the tapered solution will have a gradient of cover soil slope shallower than that of the artificial sealing layer in the system.

Giroud et al. (1995a) and Koerner (2005) proposed analytical methods to calculate the factor of safety for the stability of the veneer slope using the tapered solution. However, only dry conditions were considered in their analytical methods, in other words the effect of seepage force build-up was not analysed. In practice, despite the introduction of drainage layers having significantly reduced the risk of seepage-induced failures, the effect of water in the cover soil and seepage force build-up need to be considered to some extent, to provide the designer with confidence about the long-term slope stability.

The effect of seepage force has been considered in analytical methods for veneer slopes with uniform thickness cover soil. Giroud et al. (1995b) considered the effect of water flow in the cover soil by including both buoyancy force and drag force in the equilibrium analysis. Slip surfaces located both above and below the geomembrane liner have been analysed. Soong and Koerner (1995) adopted the seepage force build-up in the cover soil (cohesiveless) slope stability analysis assuming a flow net parallel to the slope. Two seepage force build-up patterns were defined: a horizontal build-up and a parallel-to-slope build-up, which were analysed using horizontal submergence ratio (HSR) and parallel submergence ratio (PSR) respectively. Jones and Dixon (1998) modified the analytical method with a parallel-to-slope seepage force build-up (i.e. using PSR) by including cohesion in the cover soil and adhesion at the interface between the cover soil and the underlying geosynthetic layer. All these analyses have shown that seepage flow can significantly reduce the factor of safety against the cover soil sliding along the artificial sealing layer.

This paper proposes an analytical method which will include the seepage force build-up in the stability analysis for the veneer slope with a tapered cover soil profile. Equations are presented for both the horizontal and parallel seepage force build-up patterns. Parametric analyses are presented to identify the effect of both seepage force build-up patterns on stability of the veneer slope using the tapered solution. It is noted that the analyses presented in this paper are for an unreinforced capping system.

\section{Stability of tapered cover soils with seepage build-up}

Soong and Koerner (1995) analysed the seepage force build-up in a uniform thickness cover soil slope stability analysis assuming two different seepage force build-up patterns, namely a horizontal build-up and a parallel-to-slope build-up; Soong and Koerner analysed these two build-up patterns by defining HSR and PSR respectively. These two different seepage force build-up patterns are adopted in this paper for the tapered cover soil analysis; however, the parallel mode needs to be modified to facilitate the geometry of the tapered solution as the flow net is no longer strictly parallel to the slope.

\subsection{Modified parallel seepage build-up}

Since the top and bottom surfaces of the tapered cover soil wedge are not parallel to each other, the conventional parallel seepage build-up may not be applicable to the tapered cover soil profile. A modified parallel seepage build-up pattern is therefore proposed. A modified parallel submergence ratio (MPSR) is defined to identify the water level in the cover soil. Figure 1 depicts the tapered soil slope and free body diagrams for the two-wedge system assuming the modified parallel seepage build-up pattern. As shown in Figure 1, MPSR is defined as the ratio between the head of water and the thickness of cover soil at the interface between the active and passive wedges, which can be expressed as

$$
\text { 1. } \operatorname{MPSR}=\frac{H_{\mathrm{w}}}{H_{\mathrm{c}}}
$$

The height of the tapered soil between the active and the passive wedges, as shown in Figure 1, can be calculated as

2. $H_{\mathrm{c}}=\left(L-\frac{D}{\sin \beta}-h_{\mathrm{c}} \tan \beta\right)(\sin \beta-\cos \beta \tan \omega)+\frac{h_{\mathrm{c}}}{\cos \beta}$

Head of water at the same location is

3. $H_{\mathrm{w}}=\operatorname{MPSR} H_{\mathrm{c}}$

Considering the active wedge, its selfweight can be calculated as

$$
\begin{aligned}
W_{\mathrm{A}}= & \gamma_{\mathrm{d}}\left[\frac{1}{4} H_{\mathrm{c}}^{2}(1-\mathrm{MPSR})^{2} \sin 2 \beta\right. \\
& \left.+\frac{1}{2}\left(H_{\mathrm{c}} \cos \beta+h_{\mathrm{c}}\right)\left(L-H_{\mathrm{c}} \sin \beta\right)(1-\mathrm{MPSR})\right] \\
+ & \gamma_{\mathrm{sat}}\left\{\frac{1}{4} H_{\mathrm{c}}^{2} \sin 2 \beta\left[1-(1-\mathrm{MPSR})^{2}\right]\right. \\
& \left.\quad+\frac{1}{2}\left(H_{\mathrm{c}} \cos \beta+h_{\mathrm{c}}\right)\left(L-H_{\mathrm{c}} \sin \beta\right) \mathrm{MPSR}\right\}
\end{aligned}
$$

4.

The seepage forces applied on the active wedge can be obtained as

5. $U_{\mathrm{n}}=\frac{\gamma_{\mathrm{w}} H\left(H_{\mathrm{w}}-h_{\mathrm{c}} \text { MPSR }\right)}{2 \tan \beta}$ 

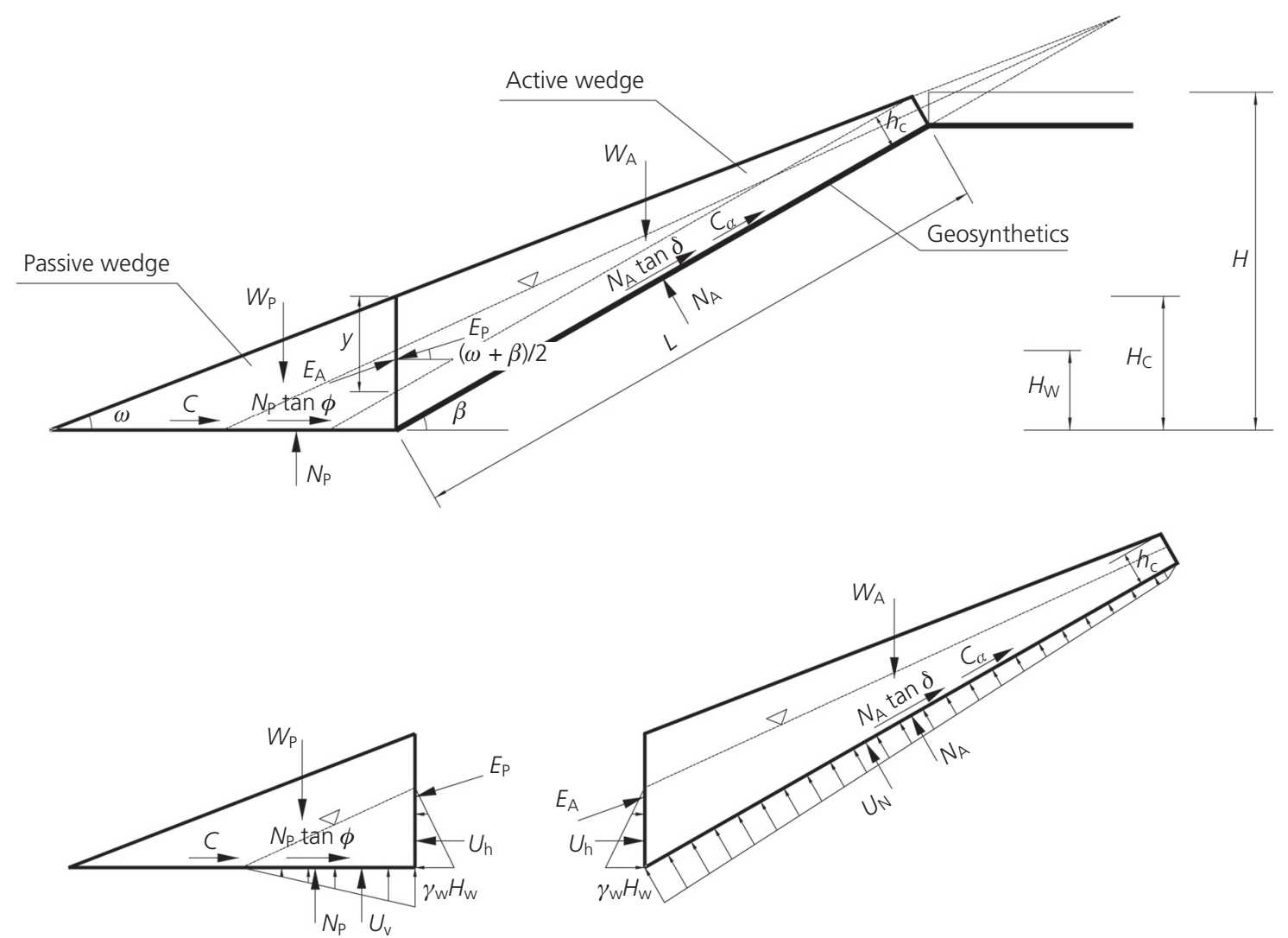

Figure 1. Free body diagram of cover soil with modified parallel seepage build-up

6. $U_{\mathrm{h}}=\frac{\gamma_{\mathrm{w}} H_{\mathrm{w}}^{2}}{2}$

Considering the force balance normal to the slip surface, the normal force can be calculated as

7. $N_{\mathrm{A}}=W_{\mathrm{A}} \cos \beta+U_{\mathrm{h}} \sin \beta-U_{\mathrm{n}}$

Also the cohesive force along the interface is obtained as

8. $C_{\alpha}=\alpha\left(L-\frac{D}{\sin \beta}\right)$

Balancing the forces in the vertical direction, the following formulation results

$$
E_{\mathrm{A}} \sin \left(\frac{\omega+\beta}{2}\right)=W_{\mathrm{A}}-\left(N_{\mathrm{A}}+U_{\mathrm{n}}\right) \cos \beta
$$

9.

$$
-\frac{N_{\mathrm{A}} \tan \delta+C_{\alpha}}{\mathrm{FS}} \sin \beta
$$

where FS is a factor of safety. Hence the interwedge force acting on the active wedge is

10. $E_{\mathrm{A}}=\frac{(\mathrm{FS})\left[W_{\mathrm{A}}-\left(N_{\mathrm{A}}+U_{\mathrm{n}}\right) \cos \beta\right]-\left(N_{\mathrm{A}} \tan \delta+C_{\alpha}\right) \sin \beta}{(\mathrm{FS}) \sin [(\omega+\beta) / 2]}$

The passive wedge is considered in a similar manner as follows

11. $W_{\mathrm{P}}=\frac{1}{2 \tan \omega}\left[\gamma_{\mathrm{d}}\left(H_{\mathrm{c}}^{2}-H_{\mathrm{w}}^{2}\right)+\gamma_{\mathrm{sat}} H_{\mathrm{w}}^{2}\right]$

12. $U_{\mathrm{v}}=\frac{\gamma_{\mathrm{w}} H_{\mathrm{w}}^{2} \cos \beta}{2 \tan \omega}$

13. $N_{\mathrm{P}}=W_{\mathrm{P}}+E_{\mathrm{P}} \sin \left(\frac{\omega+\beta}{2}\right)-U_{\mathrm{v}}$

14. $C=\frac{c^{\prime}}{\tan \omega} H_{\mathrm{c}}$ 
Balancing the forces in the horizontal direction, the following formulation results

15.

$$
E_{\mathrm{P}} \cos \left(\frac{\omega+\beta}{2}\right)=\frac{C+N_{\mathrm{P}} \tan \phi}{\mathrm{FS}}-U_{\mathrm{h}}
$$

Hence the interwedge force acting on the passive wedge is

$$
E_{\mathrm{P}}=\frac{C+\left(W_{\mathrm{P}}-U_{\mathrm{v}}\right) \tan \phi-U_{\mathrm{h}}(\mathrm{FS})}{(\mathrm{FS}) \cos \left(\frac{\omega+\beta}{2}\right)-\sin \left(\frac{\omega+\beta}{2}\right) \tan \phi}
$$

By setting $E_{\mathrm{A}}=E_{\mathrm{P}}$, the following equation can be arranged in the quadratic equation form

17. $a(\mathrm{FS})^{2}+b(\mathrm{FS})+c=0$

where

18. $a=\left[W_{\mathrm{A}}-\left(N_{\mathrm{A}}+U_{\mathrm{n}}\right) \cos \beta\right] \cos \left(\frac{\omega+\beta}{2}\right)+U_{\mathrm{h}} \sin \left(\frac{\omega+\beta}{2}\right)$

$$
b=-\left\{\begin{array}{c}
{\left[W_{\mathrm{A}}-\left(N_{\mathrm{A}}+U_{\mathrm{n}}\right) \cos \beta\right] \sin \left(\frac{\omega+\beta}{2}\right) \tan \phi} \\
+\left(N_{\mathrm{A}} \tan \delta+C_{\alpha}\right) \sin \beta \cos \left(\frac{\omega+\beta}{2}\right) \\
+\left[\left(W_{\mathrm{P}}-U_{\mathrm{v}}\right) \tan \phi+C\right] \sin \left(\frac{\omega+\beta}{2}\right)
\end{array}\right\}
$$

20. $c=\left(N_{\mathrm{A}} \tan \delta+C_{\alpha}\right) \sin \beta \sin \left(\frac{\omega+\beta}{2}\right) \tan \phi$

The resulting factor of safety value can then be obtained as

21. $\mathrm{FS}=\frac{-b+\sqrt{b^{2}-4 a c}}{2 a}$

\subsection{Horizontal seepage build-up}

Figure 2 shows the free body diagrams of both the active and passive wedges using horizontal seepage build-up pattern. HSR is defined as the ratio between the height of horizontal water table $\left(H_{\mathrm{w}}\right)$ and the total height of slope $(H)$. All the other symbols are identical to those used in the notation.

The factor of safety for taper cover soils with a horizontal seepage build-up pattern can be calculated by the two-wedge analysis applied to the parallel pattern; in other words Equation 21 is still valid. However, the $a, b$ and $c$ terms shown in the equation have different expressions owing to the new definitions for selfweights and seepage forces.
For the case of $H \leq H_{\mathrm{c}}$, the following revised terms should be adopted

$$
\begin{aligned}
& W_{\mathrm{A}}=\gamma_{\mathrm{d}}\left[\frac{1}{4} H_{\mathrm{c}}^{2} \sin 2 \beta+\frac{1}{2}\left(H_{\mathrm{c}} \cos \beta+h_{\mathrm{c}}\right)\left(L-H_{\mathrm{c}} \sin \beta\right)\right. \\
&\text { 22. } \left.\quad-\frac{H_{\mathrm{w}}^{2}}{2 \tan \beta}\right]+\gamma_{\mathrm{sat}}\left(\frac{H_{\mathrm{w}}^{2}}{2 \tan \beta}\right)
\end{aligned}
$$

23. $U_{\mathrm{n}}=\frac{\gamma_{\mathrm{w}} H_{\mathrm{w}}^{2}}{2 \tan \beta}$

24. $U_{\mathrm{h}}=\frac{\gamma_{\mathrm{w}} H_{\mathrm{w}}^{2}}{2}$

25. $W_{\mathrm{P}}=\gamma_{\mathrm{d}} \frac{\left(H_{\mathrm{c}}-H_{\mathrm{w}}\right)^{2}}{2 \tan \omega}+\gamma_{\mathrm{sat}} \frac{\left(2 H_{\mathrm{c}}-H_{\mathrm{w}}\right) H_{\mathrm{w}}}{2 \tan \omega}$

26. $U_{\mathrm{v}}=\frac{\gamma_{\mathrm{w}} H_{\mathrm{w}} H_{\mathrm{c}}}{2 \tan \omega}$

While for the case of $H_{\mathrm{w}} \geq H_{\mathrm{c}}$, the following definitions should be revised

$$
\begin{aligned}
W_{\mathrm{A}}=\gamma_{\mathrm{d}}\left[\frac{1}{4} H_{\mathrm{c}}^{2} \sin 2 \beta+\frac{1}{2}\left(H_{\mathrm{c}} \cos \beta+h_{\mathrm{c}}\right)\left(L-H_{\mathrm{c}} \sin \beta\right)\right. \\
\left.\quad-\frac{H_{\mathrm{c}}^{2}}{2 \tan \beta}-\left(\frac{H_{\mathrm{w}}^{2}-H_{\mathrm{c}}^{2}}{2 \tan \beta}-\frac{\left(H_{\mathrm{w}}-H_{\mathrm{c}}\right)^{2}}{2 \tan \omega}\right)\right] \\
+\gamma_{\mathrm{sat}}\left[\frac{H_{\mathrm{w}}^{2}}{2 \tan \beta}+\left(\frac{H_{\mathrm{w}}^{2}-H_{\mathrm{c}}^{2}}{2 \tan \beta}-\frac{\left(H_{\mathrm{w}}-H_{\mathrm{c}}\right)^{2}}{2 \tan \omega}\right)\right]
\end{aligned}
$$

28. $U_{\mathrm{n}}=\frac{\gamma_{\mathrm{w}}}{2}\left[\frac{H_{\mathrm{w}}}{\tan \beta}-\frac{\left(H_{\mathrm{w}}-H_{\mathrm{c}}\right)^{2}}{\tan \omega}\right]$

29. $U_{\mathrm{h}}=\frac{\gamma_{\mathrm{w}} H_{\mathrm{c}}^{2}}{2}$

30. $W_{\mathrm{P}}=\gamma_{\mathrm{sat}} \frac{H_{\mathrm{c}}^{2}}{2 \tan \omega}$

31. $U_{\mathrm{v}}=\frac{\gamma_{\mathrm{w}} H_{\mathrm{c}}^{2}}{2 \tan \omega}$

\section{Verification}

An example problem illustrated by Soong and Koerner (1995) has been used to verify the proposed solutions. The slope has uniform thickness cover soil with the geometry and material properties given in Table 1. 


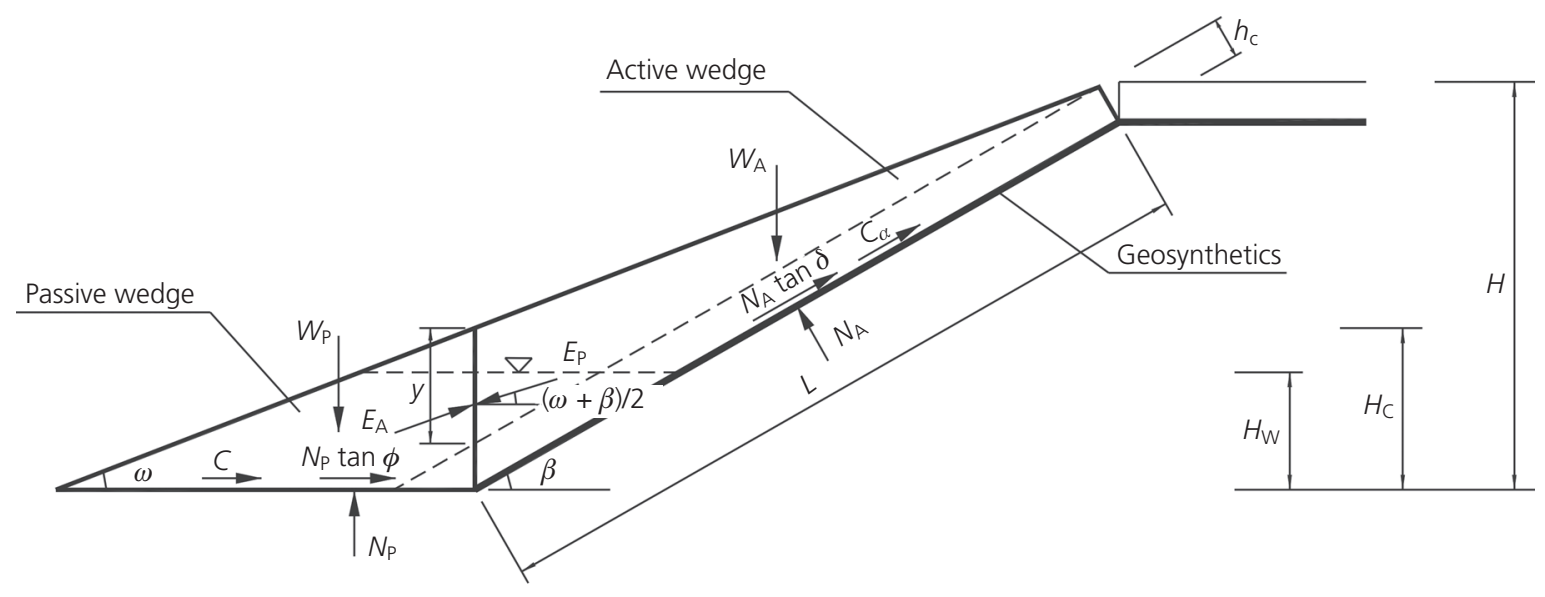

(1) $H_{w} \leq H_{C}$
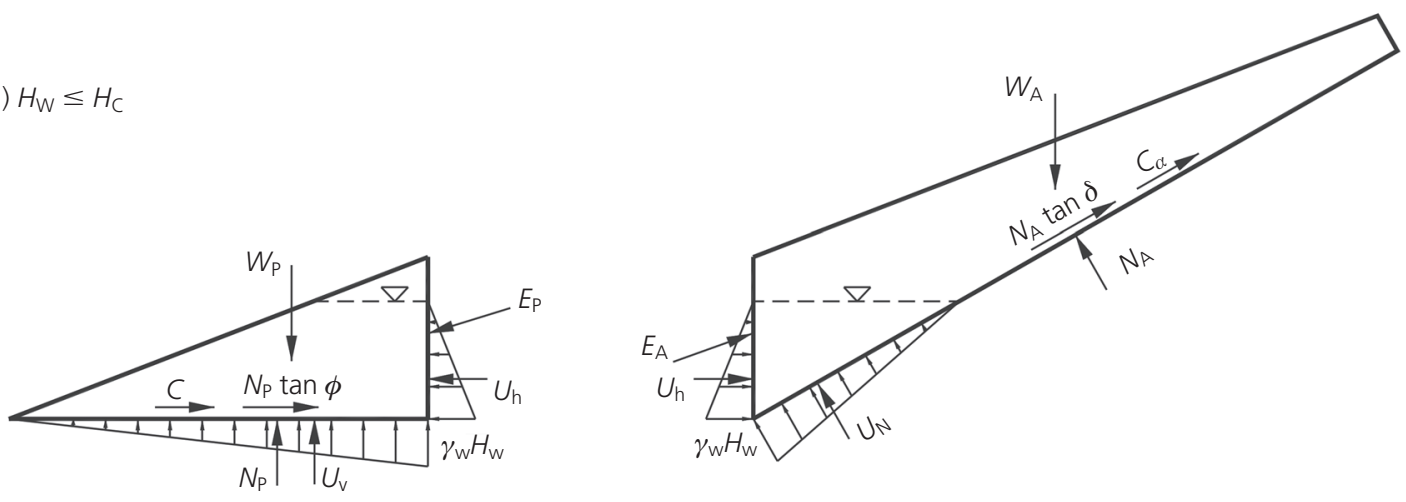

(2) $H_{w}>H_{C}$
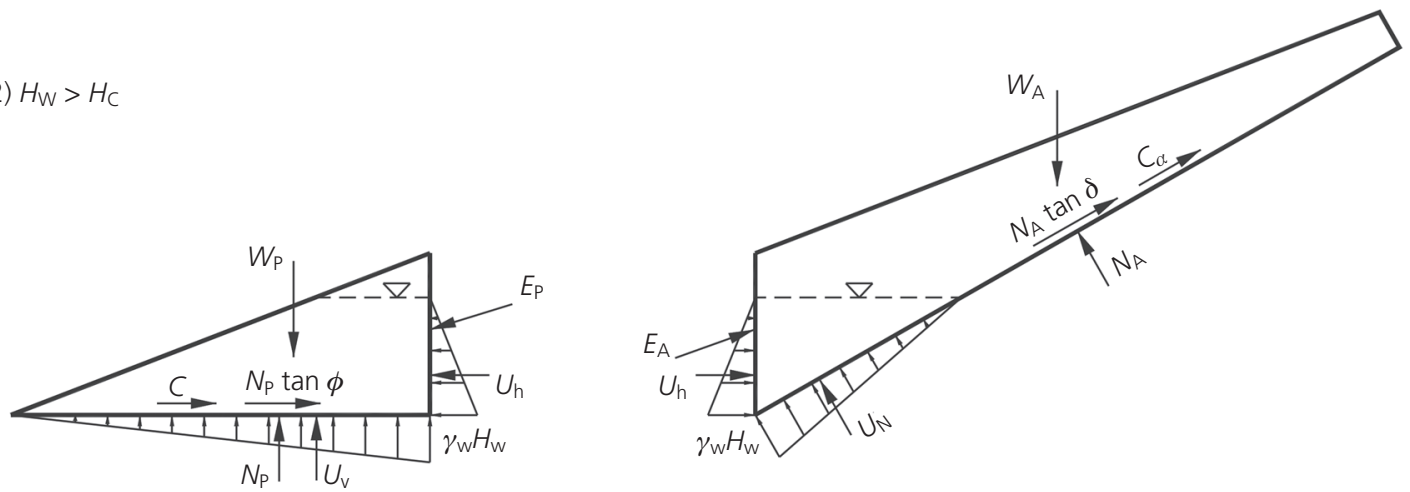

Figure 2. Free body diagram of cover soil with horizontal seepage build-up

Cover soil dry unit weight, $\gamma_{\text {dry }}$

Cover soil saturated unit weight, $\gamma_{\text {sat }}$

Cover soil friction angle, $\phi$

Interface friction angle, $\delta$

Cover soil thickness, $h$

Slope angle, $\beta$

Slope height, $H$

Table 1. Slope geometry and material properties
$18 \mathrm{kN} / \mathrm{m}^{3}$

$21 \mathrm{kN} / \mathrm{m}^{3}$

$30^{\circ}$

$22^{\circ}$

$0.9 \mathrm{~m}$

$18.4^{\circ}(1 \mathrm{v}: 3 \mathrm{~h})$

$10 \mathrm{~m}$

Factors of safety against cover soil sliding have been calculated by the proposed solutions with modified parallel and horizontal submergence ratios of $0,0 \cdot 2,0 \cdot 5$ and $1 \cdot 0$. Results have been listed in Table 2 together with those calculated by the methods proposed by Soong and Koerner (1995), and Jones and Dixon (1998). It can be seen that the results using different approaches are almost identical with insignificant discrepancies, which demonstrates that the proposed solutions are appropriate. 


\begin{tabular}{|c|c|c|c|c|c|}
\hline \multirow[t]{2}{*}{ Submergence ratio, SR } & \multicolumn{2}{|c|}{ Soong and Koerner (1995) } & \multirow{2}{*}{$\frac{\text { Jones and Dixon (1998) }}{\text { PSR }}$} & \multicolumn{2}{|c|}{ Tapered solutions } \\
\hline & PSR & HSR & & MPSR & HSR \\
\hline$S R=0$ & $1 \cdot 33$ & 1.33 & 1.33 & 1.32 & $1 \cdot 32$ \\
\hline$S R=0 \cdot 2$ & $1 \cdot 19$ & $1 \cdot 17$ & $1 \cdot 19$ & $1 \cdot 18$ & $1 \cdot 17$ \\
\hline$S R=0.5$ & 1.00 & 0.98 & 1.00 & 0.99 & 0.97 \\
\hline$S R=1.0$ & 0.72 & 0.72 & 0.71 & 0.68 & 0.69 \\
\hline
\end{tabular}

${ }^{a}$ Factors of safety have been measured from the graph

Table 2. Verification of the proposed solutions with uniform thickness cover soil

The cover soil slope is then tapered to have a gradient of $1 \mathrm{v}: 4 \mathrm{~h}$ $\left(\omega=14^{\circ}\right)$; the factors of safety are calculated by the proposed solutions and comparison is carried out for the two seepage build-up patterns. The results are presented in Table 3. The factors of safety using different submergence ratios have been improved by tapering the cover soil slope to a shallow slope angle. For example, the factor of safety for a submergence ratio of 1 (i.e. saturated) has increased from approximately 0.7 to unity, indicating a limit equilibrium state. It is noted that a minimum factor of safety of 1.3 is usually considered acceptable in the practice of slope stability analysis.

The differences between the factors of safety calculated by the approaches assuming the modified parallel seepage build-up and the horizontal seepage build-up appear to be dependent on the degree of saturation, as shown in Figure 3. The factors of safety are identical for the dry condition. For the fully saturated scenario (i.e. with a submergence ratio of 1.0) the difference between the results is minor. The greatest difference is obtained at the half saturated scenario (i.e. with a submergence ratio of 0.5 ), with the gap closing gradually towards dry and fully saturated conditions.

\section{Parametric study}

Parametric analyses are carried out to examine the sensitivities of different input parameters. A scheme of the sensitivity analysis is shown in Table 4, showing geosynthetic slope angle

\begin{tabular}{lll}
\hline Submergence ratio, SR & MPSR & HSR \\
\hline SR $=0$ & 1.88 & 1.88 \\
SR $=0.25$ & 1.68 & 1.61 \\
SR $=0.5$ & 1.46 & 1.28 \\
SR $=0.75$ & 1.22 & 1.10 \\
SR $=1.0$ & 0.98 & 1.00
\end{tabular}

Table 3. Factors of safety calculated by tapered solutions with different seepage build-up patterns $(\beta)$, cover soil slope angle $(\omega)$, height of slope $(H)$, interface friction angle $(\delta)$, cover soil friction angle $(\phi)$ and thickness of cover soil at crest $\left(h_{\mathrm{c}}\right)$. Parameter values that were used in the example analysis are highlighted in the table.

Figures 4-9 present the sensitivity analysis results, in which the factors of safety calculated for three different saturation levels of the cover soil (dry, half saturated and full saturated) are plotted against all relevant parameters. The factors of safety calculated for the dry condition using modified parallel and horizontal seepage build-up modes are identical, therefore only a single set of data $(\mathrm{SR}=0)$ is plotted in each figure. For the fully saturated condition, the factors of safety calculated for the two seepage build-up modes are almost identical for all the analyses and both are presented. The greatest gap between the results analysed by the two modes is identified at the half saturated condition for all the sensitivity analyses. These findings are consistent with those identified in the example case (Figure 3).

Figure 4 shows the sensitivity analysis result for the geosynthetic slope angle. Analyses for four different geosynthetic slope

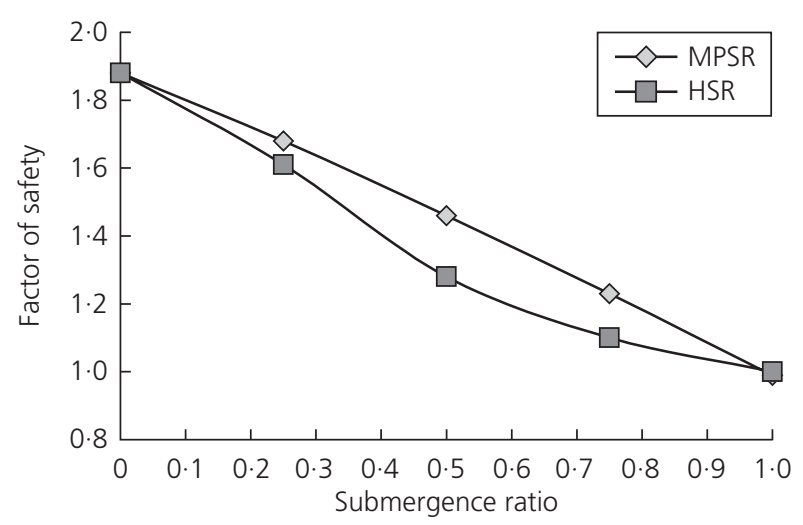

Figure 3. Comparison between tapered solutions with different seepage build-up patterns 


\begin{tabular}{|c|c|c|c|c|c|c|}
\hline Parameter & $\begin{array}{l}\text { Geosynthetic slope } \\
\text { angle, } \beta \text { : deg }\end{array}$ & $\begin{array}{l}\text { Soil slope } \\
\text { angle, } \omega \text { : deg }\end{array}$ & $\begin{array}{l}\text { Height of } \\
\text { slope, H: m }\end{array}$ & $\begin{array}{l}\text { Interface } \\
\text { friction, } \delta \text { : deg }\end{array}$ & $\begin{array}{l}\text { Soil friction, } \\
\phi \text { : deg }\end{array}$ & $\begin{array}{l}\text { Thickness of cover soil } \\
\text { at crest, } h_{c}: m\end{array}$ \\
\hline$\beta$ & $\begin{array}{l}14.0(1 \mathrm{v}: 4 \mathrm{~h}) \\
\mathbf{1 8 . 4}(1 \mathrm{v}: 3 \mathrm{~h}) \\
26 \cdot 6(1 \mathrm{v}: 2 \mathrm{~h}) \\
45 \cdot 0(1 \mathrm{v}: 1 \mathrm{~h})\end{array}$ & 14.0 & 10 & 22 & 30 & 0.9 \\
\hline$\omega$ & 18.4 & $\begin{array}{r}9.5(1 v: 6 h) \\
11 \cdot 3 \text { (1v: 5h) } \\
\mathbf{1 4 . 0}(1 v: 4 h) \\
18.4(1 v: 3 h)\end{array}$ & 10 & 22 & 30 & 0.9 \\
\hline$H$ & 18.4 & 14.0 & $\begin{array}{l}10 \\
15 \\
20 \\
25 \\
30\end{array}$ & 22 & 30 & 0.9 \\
\hline$\delta$ & 18.4 & 14.0 & 10 & $\begin{array}{l}14 \\
18 \\
22 \\
26 \\
30\end{array}$ & 30 & 0.9 \\
\hline$\phi$ & 18.4 & 14.0 & 10 & 22 & $\begin{array}{l}20 \\
25 \\
30 \\
35 \\
40\end{array}$ & 0.9 \\
\hline$h_{c}$ & 18.4 & 14.0 & 10 & 22 & 30 & $\begin{array}{l}0.3 \\
0.6 \\
\mathbf{0 . 9} \\
1.2 \\
1.5\end{array}$ \\
\hline
\end{tabular}

Table 4. Scheme of parametric study

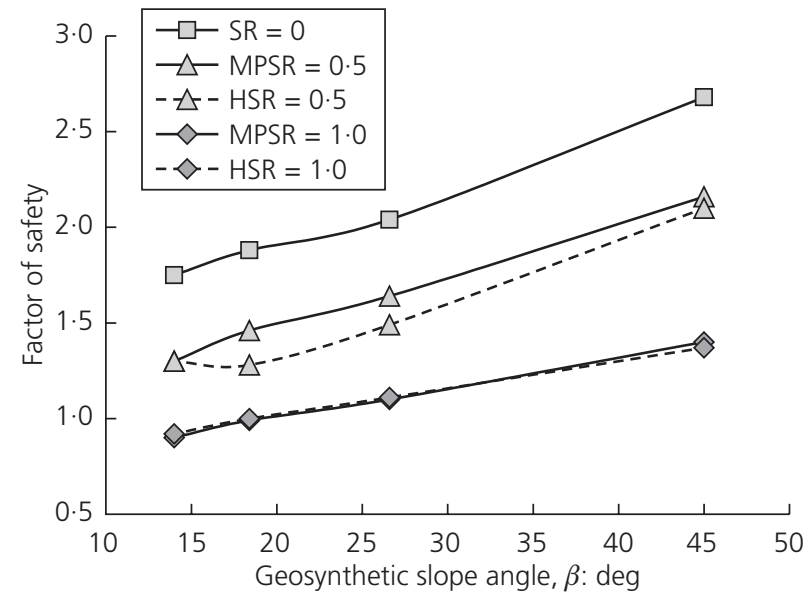

Figure 4. Sensitivity analysis of geosynthetic slope angle angles $\left(14^{\circ}, 18.4^{\circ}, 26.6^{\circ}\right.$ and $\left.45^{\circ}\right)$ are carried out for both modified parallel and horizontal seepage build-up modes, with slope angle of the cover soil being maintained at $14^{\circ}$. The factors of safety calculated for dry, half saturated and fully saturated conditions all show an increase with steeper geosynthetic slopes. The results confirm that the tapered solution would improve the stability of the cover soil. Thicker cover soil at the lower part of the slope provides higher passive pressure and therefore higher factors of safety.

Figure 5 shows the sensitivity of the cover soil slope angle to the calculated factors of safety under different submergence ratios. Analyses for four different cover soil slope angles $\left(9.5^{\circ}, 11.3^{\circ}\right.$, $14^{\circ}$ and $\left.18.4^{\circ}\right)$ are carried out for both modified parallel and horizontal seepage build-up modes, with slope angle of the cover soil being maintained at $18 \cdot 4^{\circ}$. The results are comparable 


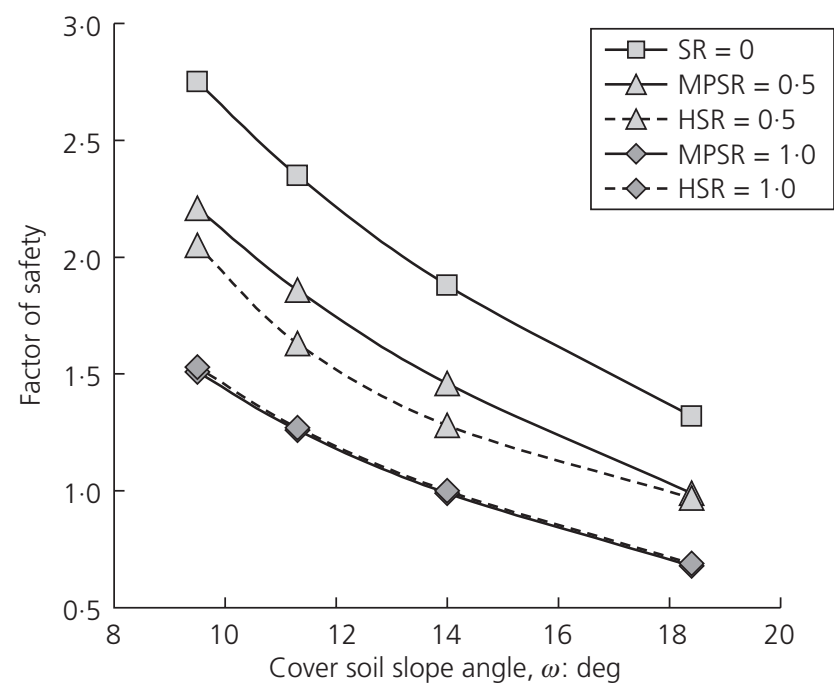

Figure 5. Sensitivity analysis of cover soil slope angle

to the geosynthetic slope angle analysis (Figure 4), that is thicker cover soil at lower parts of the slope with shallower cover soil slope angle gives higher factors of safety.

Figure 6 shows the sensitivity analysis result for the slope height. It can be seen that increasing the slope height from $10 \mathrm{~m}$ to $30 \mathrm{~m}$ results in a very small improvement in the calculated factors of safety. Figure 7 shows the sensitivity of the interface friction angle to the calculated factors of safety. With a higher interface friction angle, inevitably there is an increase for the calculated factor of safety. Similar results are obtained in the sensitivity analysis for the internal friction angle of the cover soil, as shown in Figure 8. Figure 9 shows

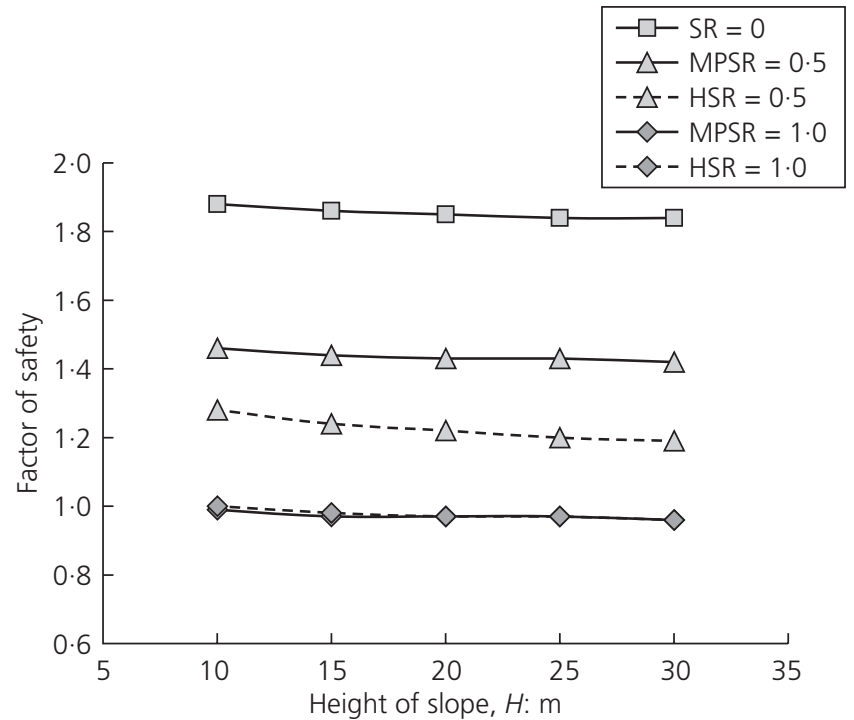

Figure 6. Sensitivity analysis of height of slope

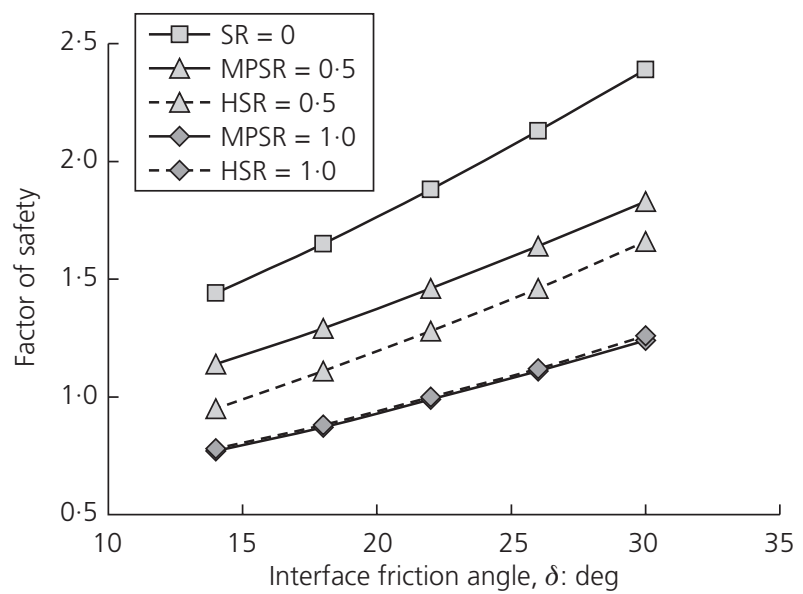

Figure 7. Sensitivity analysis of interface friction angle

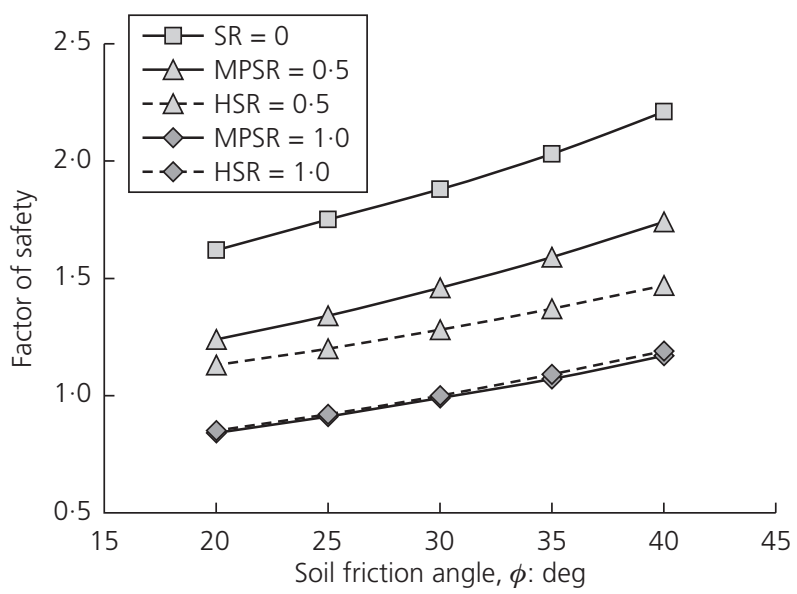

Figure 8. Sensitivity analysis of soil friction angle

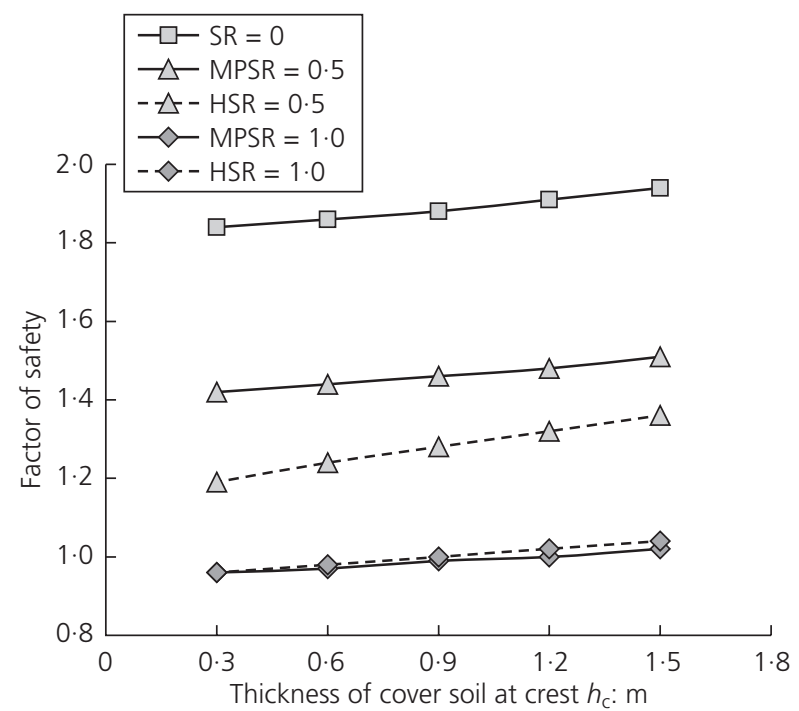

Figure 9. Sensitivity analysis of thickness of cover soil at crest 
that increasing the thickness of cover soil at the crest slightly improves the factors of safety.

\section{Discussion and conclusions}

Equations for the stability analysis of the veneer slope with a tapered cover soil profile are developed for both parallel (modified) and horizontal seepage force build-up. The proposed analytical methods are verified by comparing the calculated factors of safety for uniform thickness cover soil (non-tapered) with those calculated from the existing methods in the literature, for example Soong and Koerner (1995) and Jones and Dixon (1998).

Two different methods using MPSR and HSR are compared by applying them to a tapered cover soil design case. The results show that the calculated factors of safety obtained by these two methods for the dry (MPSR or HSR $=0$ ) condition are the same, and for the fully saturated (MPSR or HSR =1) conditions are almost identical. Discrepancies between the calculated factors of safety using the two methods are observed for the different saturated levels between the dry and fully saturated conditions. The greatest difference is identified at the half saturated condition (MPSR or HSR $=0.5$ ), with 1.46 obtained for the parallel seepage force build-up and 1.28 for the horizontal seepage force build-up. This may be because the horizontal seepage build-up results in higher water content at lower slope and therefore a heavier active wedge, giving lower factors of safety. Since the tapered profile has thicker cover soil at the lower slope, the horizontal seepage build-up may be more realistic compared with the parallel pattern for uniform thickness cover soil over an impermeable liner. In addition, lower factors of safety should represent more conservative results. It is therefore recommended that the horizontal seepage build-up should be used in future design practice.

The parametric analyses of geosynthetic and cover soil slope angles confirmed that thicker cover soil at lower parts of the slope provide higher passive pressure and therefore higher factors of safety. The other parametric studies show that the shear strengths of the interface and the cover soil can both have apparent influence on the veneer slope stability of the tapered cover soil profile, while the slope height and thickness of cover soil have very limited influence.

\section{REFERENCES}

Giroud JP, Williams ND, Pelte T and Beech JF (1995a)

Stability of geosynthetic-soil layered systems on slopes. Geosynthetic International 2(6): 1115-1148.

Giroud JP, Bachus RC and Bonaparte R (1995b) Influence of water flow on the stability of geosynthetic-soil layered systems on slopes. Geosynthetic International 2(6): 1149-1180.

Jones DRV and Dixon N (1998) The stability of geosynthetic landfill lining systems. In Geotechnical Engineering of Landfills (Dixon N, Murray EJ and Jones DRV (eds)). Thomas Telford, London, UK, pp. 99-117.

Koerner RM (2005) Designing with Geosynthetics, 5th edn. Pearson Prentice-Hall, New Jersey, USA.

Soong TY and Koerner RM (1995) Seepage induced slope instability. Proceedings of the 9th GRI Conference, Philadelphia, USA. Elsevier, New York, USA, pp. 235-255.

\section{WHAT DO YOU THINK?}

To discuss this paper, please email up to 500 words to the editor at journals@ice.org.uk. Your contribution will be forwarded to the author(s) for a reply and, if considered appropriate by the editorial panel, will be published as a discussion in a future issue of the journal.

Proceedings journals rely entirely on contributions sent in by civil engineering professionals, academics and students. Papers should be 2000-5000 words long (briefing papers should be 1000-2000 words long), with adequate illustrations and references. You can submit your paper online via www.icevirtuallibrary.com/content/journals, where you will also find detailed author guidelines. 